\title{
Comparison of ecosystem services provided by grasslands with different utilization patterns in China's Inner Mongolia Autonomous Region
}

\author{
DU Bingzhen ${ }^{1,3},{ }^{*}$ ZHEN Lin ${ }^{1,2}$, HU Yunfeng ${ }^{1,2}$, YAN Huimin ${ }^{1,2}$, DE GROOT Rudolf ${ }^{3}$, \\ LEEMANS Rik ${ }^{3}$
}

1. Institute of Geographic Sciences and Natural Resources Research, CAS, Beijing 100101, China;

2. Resource and Environment, University of Chinese Academy of Sciences, Beijing 100049, China;

3. Environmental Systems Analysis Group, Wageningen University and Research, Droevendaalsesteeg 3, 6700 AA Wageningen, The Netherlands

\begin{abstract}
Although several previous studies in Inner Mongolia examined the effects of ecological conservation on the delivery of ecosystem services, they were often limited in scope (few ecosystem services were assessed) and often suffered from confounding by spatial variation. In this study, we examined the impact of conservation measures (changes in grassland utilization patterns) on the provision of selected ecosystem services in three types of grasslands (meadow steppe in Hulun Buir, typical steppe in Xilin Gol, and semi-desert steppe in Ordos) in Inner Mongolia. We examined five utilization patterns: no use (natural grasslands), light use, moderate use, intensive use, and recovery sites (degraded sites protected from further use). Through household surveys and vegetation and soil surveys, we measured the differences in ecosystem services among the different grassland utilization patterns. We also identified spatial factors that confounded the quantification of ecosystem services in different types of grasslands. We found that light use generally provided high levels of ecosystem services in meadow steppe and typical steppe, with the main differences in the supporting ecosystem services. Surprisingly, we found no consistently positive impacts of strict conservation activities across the sites, since the results varied spatially and with respect to differences in the land-use patterns. Our study suggests that appropriate grassland utilization patterns can enhance the supply of ecosystem services and reduce negative effects on both household livelihoods and the environment.
\end{abstract}

Keywords: ecosystem services; grasslands utilization pattern; natural resource management; soil; vegetation; household livelihoods

\section{Introduction}

\subsection{Background and problem statement}

Ecosystem services are the benefits that people derive from ecosystems, and represent the

Received: 2017-05-23 Accepted: 2017-10-23

Foundation: National Natural Science Foundation of China, No.41671517; National Key Research and Development Program of China, No.2016YFC0503700

Author: Du Bingzhen (1981-), PhD Candidate, specialized in ecosystem services, ecological restoration, and eco- compensation. E-mail: dubingzhen@hotmail.com

*Corresponding author: Zhen Lin, Professor, E-mail: zhenl@igsnrr.ac.cn 
conditions and processes through which ecosystems and the species sustain and satisfy the needs of human life (Daily, 1997; Deng et al., 2016). The rapid economic growth that has occurred since the 1950s has led to serious environmental threats caused by humans, as we have consumed the services provided by natural ecosystems more rapidly and extensively than in any comparable period of human history. As a result of this unsustainable use, the Millennium Ecosystem Assessment (MEA, 2003) reported that 15 of the world's 24 ecosystem services are declining. As these services are essential for human well-being, it is increasingly urgent that we understand the interactions between humans and their ecological environment that result from the consumption and utilization of ecosystem services (Du et al., 2014; Liu et al., 2007).

The analysis of ecosystem services has become an important source of data that support policy development and the management of natural resources (Crossman et al., 2013). The analysis of ecosystem services commonly focuses on the supply of immediate, direct benefits to humans, such as provisioning services (MEA, 2005), and decision-making therefore ignores the regulating and supporting services that permit these provisioning sources to exist (Abson and Termansen, 2011). However, shifts in management philosophy towards maintaining the regulating and supporting services are increasingly advocated given the threats these services pose to the continued supply of provisioning services as a result of climate change and human interventions. This increasing understanding of the interdependencies among services have led managers to understand the need to seek compromises for the trade-offs among the different services (Prober et al., 2012; Xue and Zhen, 2018).

A key element for the maintenance of multiple ecosystem services is to identify and account for changes in the intensity of land-use patterns (e.g., plant cultivation, forestry, livestock activities) in the policy development process. Indeed, these patterns depend on several services (Power, 2010). However, the changes associated with the development of these patterns often have important negative impacts on ecosystem services in the medium and long term that impair the land's ability to continue sustaining such activities (Kareiva et al., 2011; Raudsepp-Hearne et al., 2010; Swinton et al., 2007). To maintain multiple ecosystem services, it is necessary to seek an optimal spatial allocation of human activities that will minimize their negative environmental impacts. Growing recognition of the need for such analyses has led to the incorporation of ecosystem analysis as a mandatory component of ecosystem management in many countries (Pan et al., 2013; Zhen and Du, 2017). In addition, there is also a critical need for new studies that reveal the simultaneous changes in provision of multiple services so that managers can better understand the tradeoffs involved in the delivery of ecosystem services and look for solutions and synergies (Bennett et al., 2009).

Unfortunately, analyses of multiple ecosystem services are problematic. For instance, researchers are typically constrained in the number and range of services they can analyze due to a lack of available datasets at relevant scales. Focusing on only two or three indicators (such as remote-sensing data for net primary productivity) runs the risk of creating an incomplete or distorted picture of the full range of services that different ecosystems or land use types provide. Most research has been theoretical, which results in excessive reliance on imperfect proxies for ecosystem services; for example, soil carbon stocks are often used as a proxy for climate regulation services. This approach limits and constrains the findings (Castro et al., 2015). In current research, a lack of focus on supporting services has made it especially difficult to compare different utilization patterns due to a mismatch of the scales of 
analysis for different services.

To solve some of these problems and improve the support for developing resourcemanagement policy in the grasslands of Inner Mongolia, we aimed to reduce the bias that results from focusing on too few services. To do so, we analyzed these grasslands, which are highly vulnerable to human activities, to provide a more comprehensive understanding of the relationships between natural resource conservation actions (which result in different land utilization patterns) and the resulting impacts on ecosystem services. We performed a household survey to understand the context for residents of this region, performed vegetation and soil surveys, and obtained expert opinions to (1) identify the major ecosystem services provided by Inner Mongolia's grassland ecosystem; (2) classify the grassland utilization patterns; and (3) assess the ecosystem services and their variations among grasslands in different geographic locations and with different utilization patterns. Our study included both sites that are managed for nature conservation and sites with a range of utilization intensities in three parts of Inner Mongolia with different geographic characteristics. The results of our research will improve grassland management in our study area by accounting for both ecological conservation and the livelihoods of residents of the region.

\subsection{Study area}

Meadow steppe, typical steppe and semi-desert steppe are the major types of grassland ecosystem from northeast to southwest of Inner Mongolia, and are most commonly used for grazing and animal production (Kang et al., 2007). Three typical study sites (Hulun Buir, Xilin Gol and Ordos) have been involved to represent this gradient in different types of grassland ecosystem, respectively. The local people in selected study sites depend mainly on animal husbandry to sustain their daily needs. The grassland ecosystem supplies almost all of the forage needed for their livestock's consumption (Zhen et al., 2010). However, the grasslands of Inner Mongolia have been experiencing serious degradation for decades that is directly threatening both the eco-environment and the sustainability of regional socio-economic development. A series of ecosystem conservation policies and countermeasures to alleviate the anthropogenic stresses on the ecosystems have been implemented by national and local governments, aiming to reverse the increasing tendency toward grassland degradation.

The policy of "Return pastures to grassland" was implemented in 1998 and extended throughout the region after several years' experience. The policy included four important measures that influence the use of grasslands (NDRC, 2014):

(1) Seasonal grazing measure allows free grazing in pastures only during a certain season (e.g., summer), typically throughout the grass growth period from April to November. During the winter, herders feed their livestock indoors (warm cattle shed) using conserved or purchased forage. This approach has been broadly implemented in Inner Mongolia, especially in slightly degraded grassland, such as that in Hulun Buir.

(2) Rotational grazing measure is mainly carried out in slightly and moderately degraded grassland, mostly in Xilin Gol but also on a small scale in Hulun Buir. In this measure, the grassland is fenced and divided into paddocks that are then used in rotation (25 to 50 day intervals), which heavily limited the time of pasture use, with the goal of leaving time for vegetation recovery. 
(3) Grazing prohibition measure has been implemented in intensely degraded grassland, especially in Ordos, to encourage grassland recovery. Because prohibited use of pasture could cause high economic losses by reducing the number of livestock. Herders can support and can lead to a requirement for high economic inputs due to the need to purchase fodder.

(4) Livestock-rearing control has the objective of lowering the human intervention on pastures by limiting the number of livestock allowed to graze in an area. Xilin Gol has been strongly influenced by this measure. The number of livestock is defined based on the carrying capacity of local grasslands, and nomadic grazing is prohibited and replaced by indoor rearing. To implement this measure, grassland fencing has been widely performed.

\section{Materials and methods}

\subsection{Identifying grassland utilization patterns}

Ecosystems may change the state in response to geographic variation, the degree of grassland utilization, and indirect impacts via management responses such as changed grazing regimes. By considering these factors, we defined five grassland utilization patterns: no use, light use, moderate use, intensive use, and recovery. Multiple methods were used to identify the grassland utilization patterns (Table 1).

Table 1 Characteristics of the five grassland utilization patterns in Inner Mongolia

\begin{tabular}{|c|c|c|c|}
\hline $\begin{array}{c}\text { Utilization } \\
\text { pattern }\end{array}$ & Features & $\begin{array}{c}\text { Degree of } \\
\text { use }\end{array}$ & Source \\
\hline No use & $\begin{array}{l}\text { - Natural grassland } \\
\text { - No degradation } \\
\text { - No grazing (no sign of trampling or livestock dung) }\end{array}$ & None & $\begin{array}{l}\text { Literature reviews } \\
\text { Expert interviews } \\
\text { Remote sensing }\end{array}$ \\
\hline Light use & $\begin{array}{l}\text { - Occasional use }(<4 \text { months from April to November) } \\
\text { - Seasonal grazing or rotational grazing } \\
\text { - Livestock number controlled }\end{array}$ & + & $\begin{array}{l}\text { data (comparison } \\
\text { of images from } \\
1995,2000,2005\end{array}$ \\
\hline $\begin{array}{c}\text { Moderate } \\
\text { use }\end{array}$ & $\begin{array}{l}\text { - Continuous use from April to November } \\
\text { - Seasonal grazing } \\
\text { - Livestock number controlled }\end{array}$ & ++ & $\begin{array}{l}\text { and } 2010 \text { ) } \\
\text { Field observations } \\
\text { (density of dung, } \\
\text { traces of grazing) }\end{array}$ \\
\hline $\begin{array}{c}\text { Intensive } \\
\text { use }\end{array}$ & $\begin{array}{l}\text { - Continuous use from April to November } \\
\text { - Mowing for winter fodder } \\
\text { - No grazing control measures }\end{array}$ & +++ & $\begin{array}{l}\text { Household surveys } \\
\text { (no. of livestock in } \\
\text { their pasture, graz- }\end{array}$ \\
\hline Recovery & $\begin{array}{l}\text { - Fencing used to exclude livestock and protect the grassland } \\
\text { - Grazing prohibition } \\
\text { - Used to be a seriously degraded area } \\
\text { - Recovering from degradation }\end{array}$ & None & $\begin{array}{l}\text { ing locations, ac- } \\
\text { tivities) }\end{array}$ \\
\hline
\end{tabular}

(1) Before we went to the field, we identified the five utilization patterns based on an intensive literature review, analysis of remote-sensing data, and interviews with experts.

(2) During the field surveys, we used the density of dung and traces of grazing as an indicator of grazing intensity.

(3) We also invited local herders to provide information on their number of livestock, grazing locations, and grazing practices (e.g. seasonal grazing, rotational grazing).

\subsection{Selection of ecosystem services indicators}

The local grassland ecosystem in Inner Mongolia provides multiple ecosystem services to the indigenous people, and it was not possible to assess all of them. Thus, we used three steps to identify the most important ecosystem services and relevant indicators: 
(1) Identifying ecosystem services through a literature review. Based on the classification schemes that have been devised, such as those of De Groot et al. (2002) and the Millennium Ecosystem Assessment (MEA, 2005), we selected a list of potential ecosystem services for consideration (Appendix 1).

(2) Identifying vital ecosystem services for Inner Mongolia grasslands. We conducted a stakeholder workshop on local grassland use perspectives in the summer of 2012 in Xilin Gol. The workshop's aim was to obtain information on the relative importance level of ecosystem services from the local perspective. We based our invitation of local stakeholders to the workshop on the concept of multi-level governance (Suškevics, 2012). On a county level, we selected participants from among local stakeholders following the recommendations of the government officials of Xilin Gol, who was responsible for grassland management and land use planning issues. On a village level, we asked the village headmen if they were interested in joining the workshop during a household survey in Xilin Gol that occurred shortly before the stakeholder workshop. The final group of stakeholder workshop included mixed members of 10 participants (3 village headmen and 7 county officials). According to the list of ecosystem services identified in the first step, we asked the stakeholders to assign weights that represented the perceived importance of each ecosystem service (very important, important and less important). Based on the results of this workshop, we identified 7 key ecosystem services, including: 3 provisioning services (food, raw materials including fodder, and fuel), two regulating services (soil retention and soil nutrients), and two supporting services (primary production and habitat). These were selected based on their high importance to sustain rural socio-economic activities and to prevent negative environmental impacts on the local grasslands.

(3) Selecting indicators for assessing the ecosystem services identified in the second step. Meat is the major food provisioning service that was driven from the grassland ecosystem, and can be represented based on the number of livestock per household. Beef and mutton were the two major types of meat produced in the study area. The raw material provisioning service can be quantified as the amount of fodder consumed by local livestock. The fuel provisioning service was based on the fact that the livestock produced dung, which was dried and used as a traditional local fuel source. Regulating services represent benefits that obtained from regulation of the environment and ecosystem processes. In this category, soils are considered the primary element (MEA, 2005). Many studies have indicated that extensive degradation of Inner Mongolia's grasslands has been accompanied by decreased regulating services, such as loss of soil nutrients and increased soil erosion and desertification (e.g. Zhang et al., 2013). We chose soil bulk density, soil water content, and soil nutrient contents as the site-specific indicators of the regulating services. Supporting services were defined as services necessary for the production of ecosystem functions. The most important product of Inner Mongolia's grasslands is livestock, and two main factors control the number of livestock: primary production and habitat (biodiversity). To avoid the bias that can result from using a single indicator, we divided primary production into aboveground biomass and the proportion of this biomass is edible. Similarly, because grasses are the dominant vegetation type in the grasslands, we used 3 biodiversity indicators to quantify the habitat characteristics: the Margalef, Shannon-Wiener and Pielou indices, which represent species richness, diversity, and evenness, respectively. Details of these indicators are presented in Section 2.3.3 and Table 2 summarizes the results of this selection process. 
Table 2 Proposed indicators for assessing ecosystem services under the different grassland utilization patterns

\begin{tabular}{|c|c|c|c|c|}
\hline $\begin{array}{l}\text { Ecosystem } \\
\text { function }\end{array}$ & $\begin{array}{l}\text { Ecosystem } \\
\text { service }\end{array}$ & Selected indicators & Data sources & $\begin{array}{l}\text { Grassland management } \\
\text { implications }\end{array}$ \\
\hline \multirow[t]{3}{*}{ Provisioning } & Meat & No. of livestock & \multirow{3}{*}{$\begin{array}{l}\text { Livelihood } \\
\text { survey }\end{array}$} & \multirow{3}{*}{$\begin{array}{l}\text { Food provision, liveli- } \\
\text { hood sustainability }\end{array}$} \\
\hline & Raw materials & Fodder & & \\
\hline & Fuel & Dry dung & & \\
\hline \multirow[t]{5}{*}{ Regulating } & Soil retention & $\begin{array}{l}\text { Soil bulk density } \\
\text { Soil water content }\end{array}$ & \multirow[t]{5}{*}{$\begin{array}{l}\text { Field sam- } \\
\text { pling plots }\end{array}$} & $\begin{array}{l}\text { Erosion defense, secu- } \\
\text { rity, agricultural produc- } \\
\text { tion }\end{array}$ \\
\hline & Soil nutrients & Soil organic matter (SOM) & & Fertile soils, decomposi- \\
\hline & & Available nitrogen (AN) & & tion of organic matter \\
\hline & & Available phosphorus (AP) & & \\
\hline & & Available potassium (AK) & & \\
\hline \multirow[t]{4}{*}{ Supporting } & $\begin{array}{l}\text { Primary pro- } \\
\text { duction }\end{array}$ & $\begin{array}{l}\text { Aboveground biomass (AGB) } \\
\text { Proportion of edible biomass }\end{array}$ & \multirow[t]{4}{*}{$\begin{array}{l}\text { Field sam- } \\
\text { pling plots }\end{array}$} & $\begin{array}{l}\text { Silage, hay for livestock, } \\
\text { food for wild species }\end{array}$ \\
\hline & $\begin{array}{l}\text { Habitat (bio- } \\
\text { diversity) }\end{array}$ & $\begin{array}{l}\text { Margalef (species richness) } \\
\text { index }\end{array}$ & & $\begin{array}{l}\text { Safeguarding of natural } \\
\text { heritage }\end{array}$ \\
\hline & & $\begin{array}{l}\text { Shannon-Wiener (species diver- } \\
\text { sity) index }\end{array}$ & & Functional diversity \\
\hline & & Pielou (species evenness) index & & \\
\hline
\end{tabular}

\subsection{Quantification of ecosystem services}

\subsubsection{Accounting for provisioning services by household surveys}

To quantify the spatial variations of actual provisioning services derived from the grasslands (semi-desert steppe, typical steppe, and meadow steppe) to sustain household needs, we conducted a questionnaire survey from June to July 2011 that was administered to 230 households, with an average of 23 households per village in 10 villages ( 3 in Hulun Buir, 3 in Xilin Gol, and 4 in Ordos; Figure 1), and received 209 valid responses (90.9\%). To explore and quantify how ecosystem conservation (the different land use patterns) affected the delivery of ecosystem services, we included the abovementioned 10 villages, which were different in geographical and ecological characteristics and socio-economic activities. In each village, we used stratified random sampling method to select households for interviews; households were only included in the survey if they comprised at least two people (typically a married couple). Based on the recommendation of Tabachnick and Fidell (2007) that the sample should include more than $50 \%$ of the total households for populations smaller than 100 households, the questionnaires were submitted to more than $65 \%$ of the total number of households in each village for our survey. We achieved a very high valid response rate $(90.9 \%)$ because the household questionnaire was applied through face to face interviews in which the respondents filled out the questionnaires with guidance from the research group. The questionnaires were gathered to sort out the information on household's demographic characteristics and socio-economic activities; quantification of household consumption of food (e.g. meat), fuel, fodder and their sources derived from grassland provisioning services; and information to help validate our preliminary classification of the grassland utilization patterns.

\subsubsection{Assessing regulating services by investigating soil properties}

We quantified regulating and supporting services by means of a vegetation and soil sample plot survey in June and July 2011, at the same time as the household questionnaire survey. 


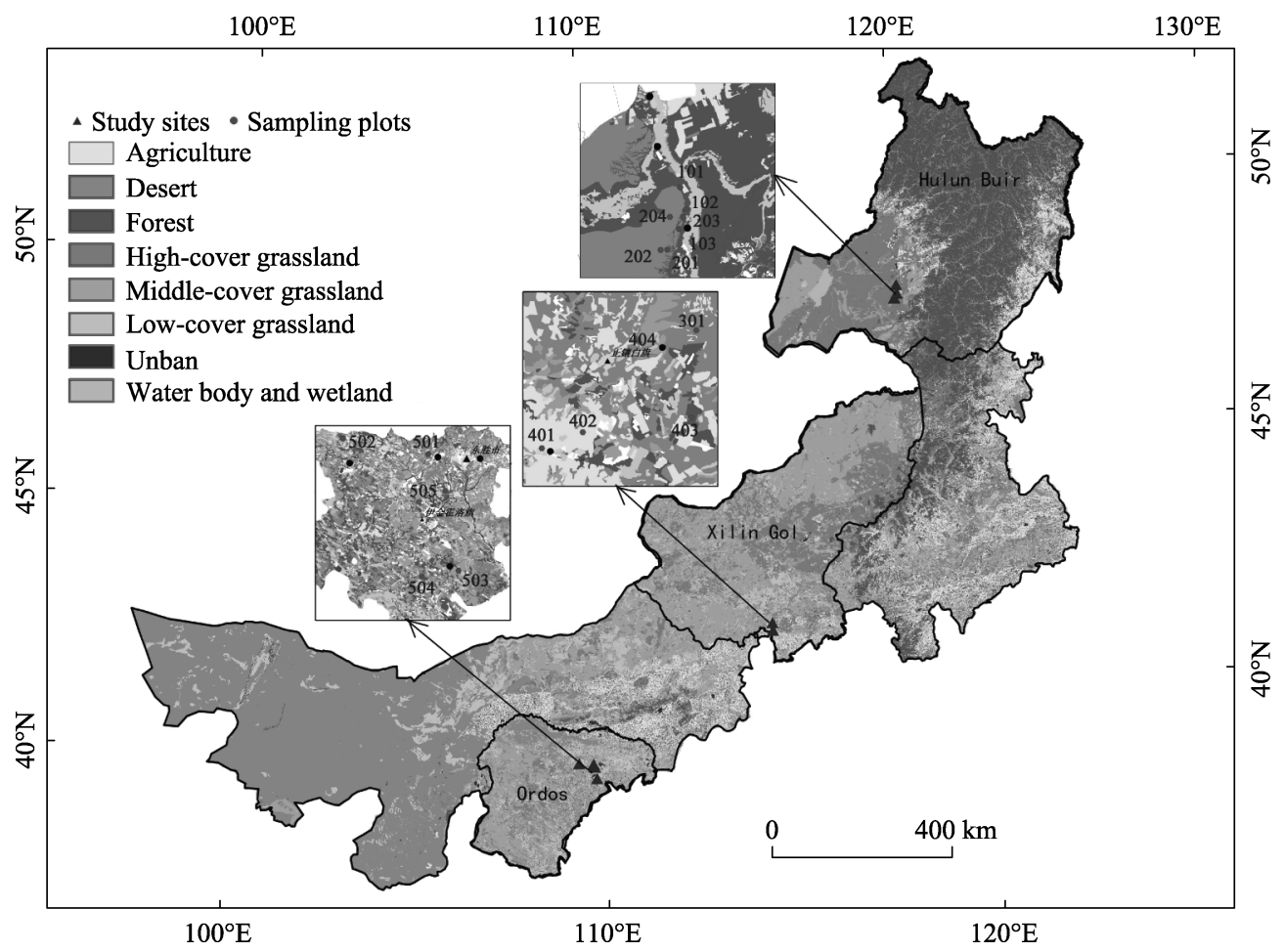

Figure 1 Location of the study area and map of the study sites. Grassland types: high-cover, vegetation cover $>50 \%$; medium-cover, vegetation cover between $25 \%$ and $50 \%$; low-cover, vegetation cover $<25 \%$. Numbers in the inset maps refer to the study plot numbers

We established sampling plots at 16 sampling sites (Table 3) from the interviewed household's rangeland to provide an estimate of the spatial variation in soil and vegetation characteristics; these included plots in semi-desert steppe (at 5 locations in Ordos), typical steppe (at 4 locations in Xilin Gol), and meadow steppe (at 7 locations in Hulun Buir). The vegetation surveys in June and July were conducted during the key growth period for the local vegetation. There were five no use sites, three light use sites, two moderate use sites, two intensive use sites (due to restrictions of regional policy, only in Hulun Buir), and four recovery sites. The main treatments for the recovery sites are fencing and replantation of grasses, the duration of recovery sites in Xilin Gol was 5 years, and durations of recovery sites in Ordos were 7-10 years (Table 3).

At each site, soil samples were collected from three soil profiles to determine soil properties to a depth of $30 \mathrm{~cm}$. Soil samples were carefully cleaned to remove plant materials and organic matter, then were air-dried and sieved through a 2-mm mesh to extract coarse materials. The three replicates were then carefully mixed to produce a single bulked sample. Analysis of soil properties was then conducted at the Physics and Chemistry Laboratory of Chinese Academy of Sciences in Beijing. Soil properties were determined following standard protocols (Bao, 2000; Brown, 1993). Each mixed soil sample was divided into two parts. One sub-sample was oven-dried at $105^{\circ} \mathrm{C}$ to constant weight to measure the bulk density and gravimetric soil water content. The other sub-sample was ground to a final size of 1 $\mathrm{mm}$ in a ball mill for analysis of the soil organic matter (SOM), available phosphorus (AP), available potassium (AK), and available nitrogen (AN) contents. 
Table 3 Basic characteristic of the study plots

\begin{tabular}{|c|c|c|c|c|c|c|c|c|c|}
\hline Location & $\begin{array}{c}\text { Plot }^{\mathrm{a}} \\
\text { number }\end{array}$ & $\begin{array}{l}\text { Longitude } \\
\left({ }^{\circ} \mathrm{N}\right)\end{array}$ & $\begin{array}{l}\text { Latitude } \\
\left({ }^{\circ} \mathrm{E}\right)\end{array}$ & $\begin{array}{c}\mathrm{T}^{\mathrm{b}} \\
\left({ }^{\circ} \mathrm{C}\right)\end{array}$ & $\begin{array}{c}\mathrm{P}^{\mathrm{c}} \\
(\mathrm{mm})\end{array}$ & $\begin{array}{l}\text { No. of } \\
\text { species }\end{array}$ & $\begin{array}{l}\text { Type of } \\
\text { grassland }\end{array}$ & Soil type & $\begin{array}{c}\text { Utilization } \\
\text { intensity }\end{array}$ \\
\hline \multirow[t]{7}{*}{$\begin{array}{l}\text { Hulun } \\
\text { Buir }\end{array}$} & 101 & 119.8 & 48.89 & -1 & 329.5 & 22 & $\begin{array}{l}\text { Meadow } \\
\text { steppe }\end{array}$ & $\begin{array}{l}\text { Medium/light } \\
\text { loam }\end{array}$ & None \\
\hline & 102 & 119.81 & 48.82 & -0.9 & 334.0 & 17 & $\begin{array}{l}\text { Meadow } \\
\text { steppe }\end{array}$ & $\begin{array}{l}\text { Medium/light } \\
\text { loam }\end{array}$ & Intensive \\
\hline & 103 & 119.77 & 48.77 & -0.8 & 336.5 & 44 & $\begin{array}{l}\text { Meadow } \\
\text { steppe }\end{array}$ & $\begin{array}{l}\text { Medium/light } \\
\text { loam }\end{array}$ & Moderate \\
\hline & 201 & 119.71 & 48.72 & -0.7 & 338.3 & 32 & $\begin{array}{l}\text { Meadow } \\
\text { steppe }\end{array}$ & $\begin{array}{l}\text { Medium/heavy } \\
\text { loam }\end{array}$ & None \\
\hline & 202 & 119.68 & 48.72 & -0.7 & 337.5 & 33 & $\begin{array}{l}\text { Meadow } \\
\text { steppe }\end{array}$ & $\begin{array}{l}\text { Heavy/medium } \\
\text { loam }\end{array}$ & None \\
\hline & 203 & 119.79 & 48.8 & -0.8 & 334.9 & 16 & $\begin{array}{l}\text { Meadow } \\
\text { steppe }\end{array}$ & $\begin{array}{l}\text { Light/sandy } \\
\text { loam }\end{array}$ & Intensive \\
\hline & 204 & 119.74 & 48.81 & -0.9 & 333.3 & 42 & $\begin{array}{l}\text { Meadow } \\
\text { steppe }\end{array}$ & $\begin{array}{l}\text { Medium/light } \\
\text { loam }\end{array}$ & Light \\
\hline \multirow[t]{4}{*}{$\begin{array}{c}\text { Xilin } \\
\text { Gol }\end{array}$} & 301 & 115.14 & 42.33 & 3.3 & 217.0 & 23 & $\begin{array}{l}\text { Typical } \\
\text { steppe }\end{array}$ & Sandy loam & Light \\
\hline & 401 & 114.88 & 42.21 & 3.4 & 210.2 & 10 & $\begin{array}{l}\text { Typical } \\
\text { steppe }\end{array}$ & $\begin{array}{l}\text { Light/sandy } \\
\text { loam }\end{array}$ & $\begin{array}{l}\text { Recovery } \\
\text { (5 years) }\end{array}$ \\
\hline & 402 & 114.95 & 42.22 & 3.4 & 210.9 & 15 & $\begin{array}{l}\text { Typical } \\
\text { steppe }\end{array}$ & $\begin{array}{l}\text { Light/sandy } \\
\text { loam }\end{array}$ & Moderate \\
\hline & 403 & 115.12 & 42.23 & 3.3 & 217.6 & 24 & $\begin{array}{l}\text { Typical } \\
\text { steppe }\end{array}$ & Light loam & None \\
\hline \multirow[t]{5}{*}{ Ordos } & 501 & 109.79 & 39.84 & 7.1 & 248.1 & 20 & $\begin{array}{l}\text { Semi-desert } \\
\text { steppe }\end{array}$ & Light loam & None \\
\hline & 502 & 109.32 & 39.92 & 7.2 & 219.8 & 19 & $\begin{array}{l}\text { Semi-desert } \\
\text { steppe }\end{array}$ & Sandy loam & $\begin{array}{l}\text { Recovery } \\
\text { (10 years) }\end{array}$ \\
\hline & 503 & 109.92 & 39.36 & 7.1 & 230.1 & 20 & $\begin{array}{l}\text { Semi-desert } \\
\text { steppe }\end{array}$ & $\begin{array}{l}\text { Dense sand, } \\
\text { sandy loam }\end{array}$ & $\begin{array}{l}\text { Recovery } \\
\text { (8 years) }\end{array}$ \\
\hline & 504 & 109.72 & 39.34 & 7.1 & 225.6 & 26 & $\begin{array}{l}\text { Semi-desert } \\
\text { steppe }\end{array}$ & $\begin{array}{l}\text { Sandy loam, } \\
\text { dense sand }\end{array}$ & Light \\
\hline & 505 & 109.87 & 39.69 & 7.1 & 247.5 & 17 & $\begin{array}{l}\text { Semi-desert } \\
\text { steppe }\end{array}$ & $\begin{array}{l}\text { Light loam, } \\
\text { sandy loam }\end{array}$ & $\begin{array}{l}\text { Recovery } \\
\text { (7 years) }\end{array}$ \\
\hline
\end{tabular}

${ }^{a}$ Locations of the plots are shown in Figure 1.

${ }^{\mathrm{b}} \mathrm{T}$ is the annual average temperature $\left({ }^{\circ} \mathrm{C}\right)$, were obtained from meteorological stations in Inner Mongolia in 2011.

${ }^{\mathrm{c}} \mathrm{P}$ is the annual average precipitation $(\mathrm{mm})$, were obtained from meteorological stations in Inner Mongolia in 2011.

\subsubsection{Assessing supporting services based on vegetation traits}

To quantify the vegetation characteristics, we harvested the aboveground biomass (AGB) in three repeated sub-plots (each $1 \mathrm{~m} \times 1 \mathrm{~m}$ ) at each plot, with similar topography and exposure to sunlight and with the sub-plots separated by every $10 \mathrm{~m}$. All living vascular plants in each quadrat were sorted according to species. Subsequently, the plant height, vegetation cover, number of individuals, and density (no. individuals per $\mathrm{m}^{2}$ ) were determined. AGB was determined by clipping the plants at ground level, and was measured after oven-drying at $65 \pm$ $5^{\circ} \mathrm{C}$ for $48 \mathrm{~h}$. The proportion of edible biomass was determined based on indigenous knowledge of the species that could be consumed by the local livestock; this proportion equaled AGB for all edible species divided by total AGB.

The grassland production data (AGB and the proportion of edible biomass) were used directly to indicate supporting services for primary production. In addition, we calculated 3 diversity indicators to represent the habitat ecosystem service: 
The Shannon-Wiener index $(H)$ was calculated as follows (Bakelaar and Odum, 1978):

$$
H=-\sum_{i=1}^{s}\left(P_{i} \ln P_{i}\right)
$$

where $S$ is the number of species and $P_{i}$ is the relative importance of species $i$ (its proportion of the total number of species). The relative importance of species is calculated as follows:

$$
P_{i}=N_{i} / N
$$

where $N_{i}$ is the number of individuals of species $i$, and $N$ is the total number of individuals of all species in the quadrat.

The Margalef index $(D)$ was calculated as follows:

$$
D=(S-1) / \ln N
$$

The Pielou index $(E)$ was calculated as follows:

$$
E=\frac{H}{\ln (S)}
$$

\section{Results and discussion}

\subsection{Provisioning services that support herder livelihoods}

Grasslands produce three main products that sustain the livelihood of herders: meat (mutton and beef), fodder (grass), and biofuel (dry dung). All three goods are directly related to the number of livestock, and the results therefore differed greatly among the three areas due to the different numbers of livestock per household (Table 4). In Hulun Buir (meadow steppe),

\begin{tabular}{|c|c|c|c|c|c|}
\hline \multirow[t]{2}{*}{ Consumptions } & \multicolumn{5}{|c|}{ Study site ${ }^{a}$} \\
\hline & & $\begin{array}{l}\text { Hulun Buir } \\
\quad(n=66)\end{array}$ & $\begin{array}{c}\text { Xilin Gol } \\
(n=71)\end{array}$ & $\begin{array}{l}\text { Ordos } \\
(n=72)\end{array}$ & $\begin{array}{l}\text { Overall } \\
(n=209)\end{array}$ \\
\hline \multicolumn{6}{|c|}{ Livestock (no. per household, \% of total) } \\
\hline & Sheep & $52.0(68.2)$ & $2.4(27.0)$ & $2.4(8.9)$ & $18.0(49.5)$ \\
\hline & Goats & $3.2(4.2)$ & $0.2(2.2)$ & $6.0(22.3)$ & $3.2(8.8)$ \\
\hline & Cattle & $18.0(23.6)$ & $4.2(47.2)$ & $0.8(3.0)$ & $7.3(20.1)$ \\
\hline & Chickens & $3.0(3.9)$ & $2.0(22.5)$ & $16.9(62.8)$ & $7.5(20.6)$ \\
\hline & Pigs & $0.1(0.1)$ & $0.1(1.1)$ & $0.8(3.0)$ & $0.4(1.1)$ \\
\hline & Total livestock & $76.3(100)$ & $8.8(100)$ & $26.9(100)$ & $37.3(100)$ \\
\hline \multicolumn{6}{|c|}{ Meat (kg per capita per year, $\%$ of total) } \\
\hline & Mutton-beef & $97.2(76.3)$ & $65.6(82.5)$ & $35.7(39.5)$ & $65.3(66.4)$ \\
\hline & Other meat ${ }^{\mathrm{b}}$ & $30.1(23.6)$ & $13.9(17.5)$ & $54.7(60.5)$ & $33.1(33.6)$ \\
\hline & Total meat & $127.3(100)$ & $79.5(100)$ & $90.4(100)$ & $98.4(100)$ \\
\hline \multicolumn{6}{|c|}{ Fuel (per capita per year) } \\
\hline & Dry dung (kg) & 2878.6 & 265.2 & 199.4 & 1407.5 \\
\hline & Coal (kg) & 2063.6 & 690.6 & 922.4 & 1203.9 \\
\hline & Electricity (CNY) & 84.4 & 135.9 & 215.0 & 146.9 \\
\hline
\end{tabular}
herding of sheep (an average of 52 per household) and cattle (18 per household) was the major economic activity. A smaller number of cattle (an average of 4.2 per household) and

Table 4 Household consumption of provisioning services

${ }^{a} n$ represents the number of households surveyed.

${ }^{\mathrm{b}}$ Other meat includes pork, chicken, and fish. 
sheep (2.4 per household) dominated economic activity in Xilin Gol (typical steppe). The productivity for livestock production per household in Xinlin Gol was only around 10\% of Hunlun Buir (76.3 per household vs. 8.8 per household). In Ordos (semi-desert steppe), a few cattle (an average of 0.8 per household) and sheep ( 2.4 per household) are raised, primarily for breeding. In Ordos, households chose to raise many smaller animals than in the other areas, such as goats (an average of 6.0 per household) and chickens (16.9 per household). This seems to be a pragmatic response to government initiatives that greatly reduce the consumption of fodder from ecosystems to prevent further degradation of the semi-desert steppe. The results of household survey show that dry dung from livestock was an important biofuel; it was widely used in all three areas, but especially in Hulun Buir, where the annual per capita consumption was $2878.6 \mathrm{~kg}$. The high consumption of dried dung can be attributed to the higher numbers of sheep and cattle. Herders used biofuel to meet the needs of daily life, including cooking, heating, and heating bath water. Due to the great reduction in the number of livestock in response to government policies to reduce grazing pressure on the ecosystem, with especially severe reductions in Xilin Gol and Ordos, dry dung cannot satisfy the household demand so households use more new forms of energy (e.g. coal, electricity) instead of dung. Table 5 shows how the ecosystem services differed among the three regions and changed as a function of the intensity of grassland use. Due to the government's conservation policies, the no use and recovery grassland utilization patterns have totally lost their provisioning services to herders. The intensive use pattern has the highest value of provisioning services, followed by the moderate and light use patterns.

\subsection{Regulating services in the different grassland utilization patterns}

\subsubsection{Soil retention}

Along the transect from northeast to southwest, soil bulk density increased (representing greater compaction), and SOM and the soil water content decreased (Table 6), indicating a decreasing ecological service for soil retention. Soil bulk density was the lowest in Hulun Buir (meadow steppe) and the highest in Ordos (semi-desert steppe). Soil water content was the highest in Hulun Buir and the lowest in Ordos, with a significant decreasing trend $(\mathrm{P} \leqslant$ 0.05 ) along with decrease of precipitation and incease of temperature (Table 3). In Hulun Buir, the no use pattern had the highest soil water content $(12 \%)$, and the intensive use pattern had the lowest soil water content (7\%). As in the case of Hulun Buir, soil water content decreased with increasing intensity of grassland use. The soil water content also increased at the recovery sites compared with the used sites (Table 5, Appendix 2).

Previous research in Xilin Gol indicated that soil retention services were correlated with decreased desertification and ecosystem degradation, and that increased soil retention services may have been responsible for a higher soil water content. Inner Mongolia is characterized by an arid to semi-arid continental climate and strongly imfluenced by tempreture and precipitaition (Yu et al., 2003). Thus, water shortages are widely observed. From 2014 statistics, the region's total water resources were $412.1 \times 10^{9} \mathrm{~m}^{3}$, and have decreased at an average rate of 5\% per year since the 1990s (IMSY, 2015). Chinese statistics suggest that desertification caused by drought is the most frequent meteorological disaster in the study area (IMSB, 2013). The drought mainly occurs between May and September, the most inportant period for grass growth. 


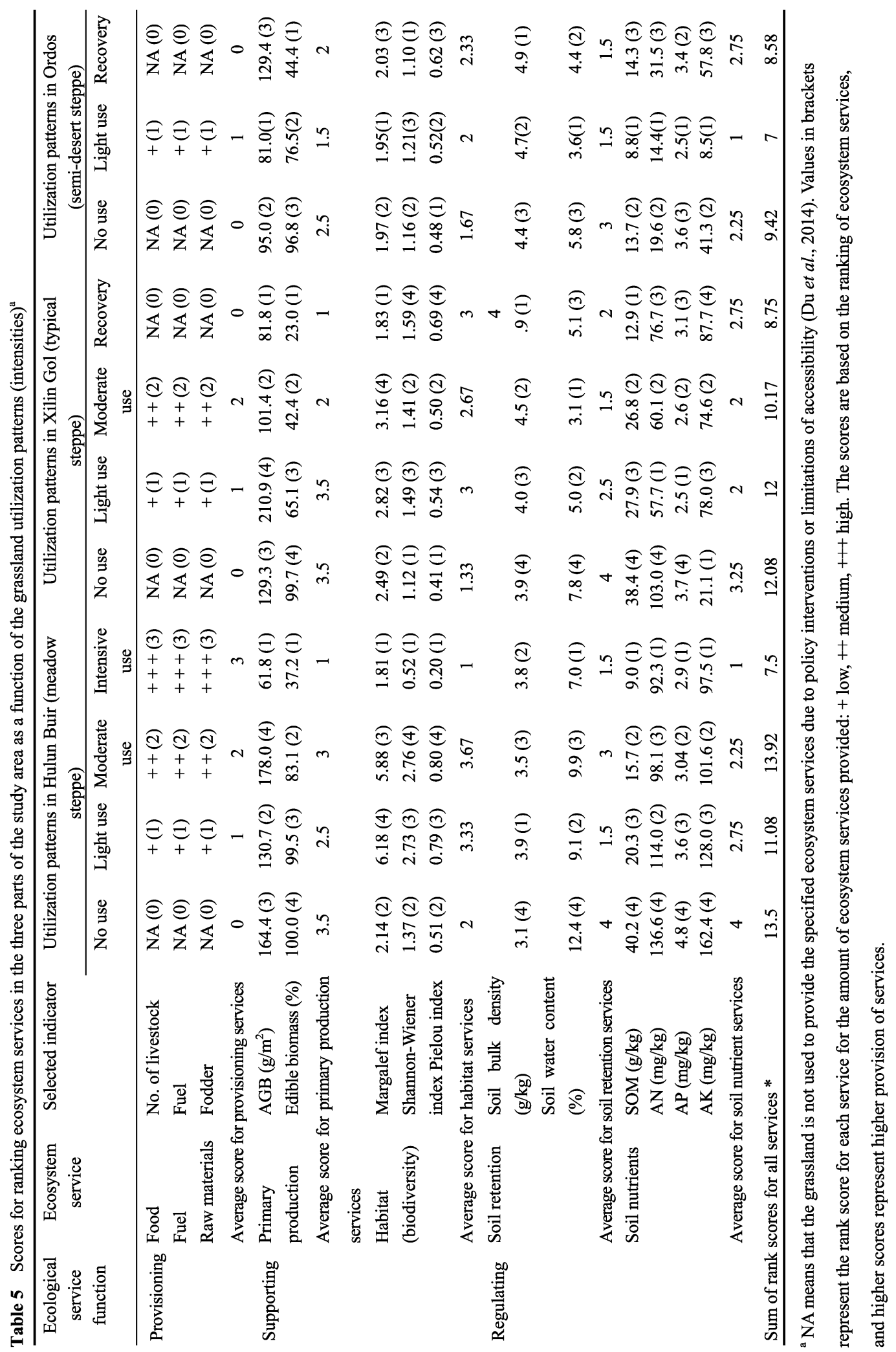


Table 6 Differences in mean soil properties among the three parts of the study area (AK, available potassium; AN, available nitrogen; AP, available phosphorus; SOM, soil organic matter)

\begin{tabular}{|c|c|c|c|c|c|c|}
\hline \multirow{2}{*}{ Site } & \multicolumn{2}{|c|}{ Soil bulk density $(\mathrm{g} / \mathrm{kg})$} & \multicolumn{2}{|c|}{$\mathrm{SOM}(\mathrm{g} / \mathrm{kg})$} & \multicolumn{2}{|c|}{ Soil water content $(\%)$} \\
\hline & Average & S.E. & Average & S.E. & Average & S.E. \\
\hline Hulun Buir (meadow steppe) & 3.40 & 0.35 & 24.98 & 17.23 & 10.04 & 4.47 \\
\hline Xilin Gol (typical steppe) & 4.50 & 0.59 & 23.4 & 12.68 & 5.22 & 4.65 \\
\hline Ordos (semi-desert steppe) & 4.60 & 0.26 & 13 & 3.24 & 4.52 & 2.12 \\
\hline \multirow[t]{2}{*}{ Site } & \multicolumn{2}{|c|}{$\mathrm{AN}(\mathrm{mg} / \mathrm{kg})$} & \multicolumn{2}{|c|}{$\mathrm{AP}(\mathrm{mg} / \mathrm{kg})$} & \multicolumn{2}{|c|}{$\mathrm{AK}(\mathrm{mg} / \mathrm{kg})$} \\
\hline & Average & S.E. & Average & S.E. & Average & S.E. \\
\hline Hulun Buir & 114.18 & 31.63 & 4.1 & 1.17 & 130.29 & 9.14 \\
\hline Xilin Gol & 64.94 & 33.94 & 3.11 & 0.54 & 93.50 & 20.11 \\
\hline Ordos & 24.10 & 15.31 & 3.24 & 0.46 & 44.4 & 30.88 \\
\hline \multirow[t]{2}{*}{ Site } & \multicolumn{2}{|c|}{$\begin{array}{c}\text { Margalef index } \\
\text { (species richness) }\end{array}$} & \multicolumn{2}{|c|}{$\begin{array}{l}\text { Shannon-Wiener index } \\
\text { (species diversity) }\end{array}$} & \multicolumn{2}{|c|}{$\begin{array}{c}\text { Pielou index } \\
\text { (species evenness) }\end{array}$} \\
\hline & Average & S.E. & Average & S.E. & Average & S.E. \\
\hline Hulun Buir & 3.83 & 1.87 & 1.87 & 0.82 & 0.61 & 0.21 \\
\hline Xilin Gol & 2.20 & 0.55 & 1.29 & 0.30 & 0.51 & 0.14 \\
\hline Ordos & 2.00 & 0.89 & 1.92 & 1.31 & 0.58 & 0.27 \\
\hline
\end{tabular}

S.E: standard error

\subsubsection{Soil nutrients}

Soil nutrient contents (SOM, AN, AP, and AK) represented nutrient regulation services. AK and AN were the highest in Hulun Buir (meadow steppe) and the lowest in Ordos (semi-desert steppe), which showed a significant decreasing trend $(\mathrm{P} \leqslant 0.05)$ along this transect (Table 6). SOM and AP also decreased along this transect, but the trend was not significant $(\mathrm{P} \geqslant 0.05)$. As was the case for soil retention services, the soil nutrient regulating service decreased in strength with increasing intensity of grassland use (Table 5). SOM, AN, $\mathrm{AP}$ and $\mathrm{AK}$ were the highest with no use in all three regions, but showed little difference between light and moderate use patterns in Xilin Gol (typical steppe). Ordos had fewer grassland use patterns, and the highest SOM, AN, AP, and AK values were found under the recovery patterns or no use. This may be because Ordos is one of the earliest demonstration sites for the grassland restoration project launched around 2000 in Inner Mongolia.

Grazing intensity is one of the factors that most strongly influence the regulating services as a result of the changes it causes in soil properties. Trampling by grazing animals increases soil bulk density and the mechanical resistance to penetration, and therefore decreases porosity, water infiltration, and aggregate stability (Evans et al., 2012). Zhou et al. (2010) reported that grazing and trampling by livestock caused deterioration of soil physical properties (e.g. soil bulk density) and increased soil vulnerability to erosion. Our results for regulating services show that soil properties (water content, SOM, and available nutrients) improve with decreasing intensity of grassland use. These results confirm that maintaining grazier densities at or below grassland carrying capacity will improve soil-related ecosystem services in the grassland of northern China, as has been suggested by Eastwood et al. (2013).

\subsection{Supporting services in different utilization patterns}

\subsubsection{Primary production}

Primary production is a fundamental ecosystem service for the whole ecosystem, and is 
closely related to other ecosystem services such as provisioning services. Meadow steppe (Hulun Buir), typical steppe (Xilin Gol), and typical steppe (Ordos) produced different amounts of AGB due to differences in their geographic characteristics (such as temperature, precipitation and soil type, and shows gradient decreasing trend from Hulun Buir to Ordos); AGB was the highest in Hulun Buir (meadow steppe) and the lowest in Ordos (semi-desert steppe) (Table 6). In general, the proportion of edible biomass decreased with decreasing precipitation and increasing intensity of grassland use (Rook et al., 2004; Yan et al., 2012). The highest values of AGB were found in the moderate use pattern in Hulun Buir and the light use pattern in Xilin Gol. The lowest AGB in Hulun Buir was found in the intensive use pattern. Our results therefore support previous research of Rook et al. (2004) and Yan et al. (2012) in which grazing does not inevitably degrade an ecosystem, and may actually increase its supporting ecosystem services if it occurs at an intensity below the carrying capacity. The proportion of edible biomass was low in the recovery pattern, at only $23 \%$ in Xilin Gol and 44\% in Ordos (Table 5, Appendix 2). The AGB of recovery site in Xilin Gol was the lowest, while that in Ordos were the highest. This is because Ordos has implemented the restoring treatments for 7-10 years, while Xilin Gol was only 5 years.

\subsubsection{Habitat}

Table 6 shows that habitat services were greater in the meadow steppe (Hulun Buir) than in the typical steppe (Xilin Gol) and semi-desert steppe (Ordos). One of the most important limiting factors is the geographic condition (e.g. temperature and precipitation) besides the utilization patterns of grasslands.

Under the different grassland utilization patterns, diversity in Hulun Buir was highest under light use, followed by moderate use, and then decreased sharply with increasing intensive use (Table 5, Appendix 3). However, the species richness (Margalef index) and evenness (Pielou index) in Hulun Buir were both the highest in the moderate use pattern, with values slightly higher than those in the light use pattern. Unlike in Hulun Buir, the species diversity and evenness of grassland in Xilin Gol decreased with utilization intensity increasing from light to moderate use. This means that the typical steppe (Xilin Gol) is more vulnerable than the meadow steppe to intensive use of the grassland. In Ordos, grazing was restricted more than in the other areas, so there was little difference in diversity among the different intensities of grassland use.

In summary, the supporting services in Hulun Buir decreased with increasing utilization intensity, which agrees with the results of Medina-Roldan et al. (2012), who found that grassland biomass production and biodiversity decreased in grazing areas because of overgrazing. In the present study, the proportion of edible biomass was relatively low at the recovery sites, although the diversity and evenness of the grassland were enhanced by conservation activities. Our results show that AGB and the three diversity indicators did not always follow a gradient of increasing intensity of grassland use in Inner Mongolia. For instance, the highest values of AGB and the Shannon-Wiener index were observed in the moderate use pattern in Hulun Buir and the light one in Xilin Gol. Xu et al. (2013) found that moderate grazing had positive effects on seedling recruitment and vegetation diversity, but that heavy grazing may alter community succession by affecting recruitment patterns.

\subsection{Ranking of ecosystem services under different grassland utilization patterns}

The results of our ranking of ecosystem services under different grassland utilization 
patterns (Table 5) show large spatial variation among the three types of grasslands in their representative areas. In Hulun Buir (meadow steppe), the moderate use pattern had the highest total score (i.e., the highest sum of the scores for provisioning, regulating, and supporting services), followed by the no use pattern; these use patterns therefore provided the highest overall ecosystem services values. The lowest values were found for intensive use. In Xilin Gol (typical steppe), the no use pattern had the highest total score, followed by the light use pattern, and these patterns therefore provided the highest overall service values; the recovery pattern produced the lowest rank score, and thus the lowest services. In contrast, the rank score in Ordos (semi-desert steppe) was the highest for no use, followed by recovery, but the scores did not differ greatly among the no use and recovery patterns.

Our data suggests that natural conservation (no use) of grasslands should be encouraged because it helps to deliver the greatest quantity of ecosystem services. However, the evidence for this argument is weaker than expected, and is sometimes equivocal. For example, the agricultural provisioning services (food, fuel, and fodder) tended to decrease with decreasing intensity of grassland use in Inner Mongolia. Eigenbrod et al (2010) also found that protected areas in England have high levels of biodiversity and carbon storage, but low levels of recreation and agriculture services. At a European scale, Burkhard et al. (2012) looked at the association between the demand for ecosystem services and different CORINE land cover classes (http://ec.europa.eu/agriculture/publi/landscape/ about.htm), and found that habitat classes that were important for conservation, such as peat bogs and natural grassland, ranked highly for their supply of regulating services, but ranked low in terms of their provisioning services. Our results of ranking ecosystem services show that the ecosystem services can be improved after 7-10 years grassland restoration. The previous research of Shan et al. (2008) also found that after the utilization of grassland fencing, the service value of steppe was significantly increased by $29.11 \%$ and $53.62 \%$ after grass restoration for $9-10$ and $12-13$ years. Our results also indicate that suitable use of grasslands can be achieved by considering differences in the resilience and capacities of different grassland types, thereby offering more effective ways to protect the grassland ecosystems. For instance, the meadow steppe has high resilience and tolerance of human activities, so the moderate use pattern can be applied in this region. In contrast, fragile ecosystems such as the semi-desert steppe in Ordos should be protected against anything more than light use.

\section{Conclusions}

For sustainable management of ecosystems to provide services, it is necessary to analyze both the ecological and socio-economic elements of the ecosystem, since complex interdependencies between humans and ecosystems strongly affect the provision of ecosystem services. Our analysis shows how we can quantitatively account for a greater amount of ecosystem services. This research provides important insights into differences among ecosystems in their ability (such as precipitation, temperature and soil type) to tolerate human disturbance (different degrees of grassland utilization patterns).

Our results demonstrate the value of a more holistic approach to the management of grasslands such as those of Inner Mongolia. Specifically, they reveal that the optimal utilization intensity differs among the study sites, with the meadow steppe (in Hulun Buir) being able to tolerate a higher level of disturbance from human activities (moderate use of grass- 
land) than the other grasslands (light use or no use) and the semi-desert steppe (in Ordos) being able to tolerate the least disturbance (no use or recovery). Our results also show how grassland utilization for livestock grazing had significant ecological consequences (decrease of ecosystem services), but there was an important interaction between the geographic condition, grassland type and utilization intensity. There were also trade-offs that must be considered. For example, meadow steppe, the ability (e.g. highest precipitation over 300 $\mathrm{mm} /$ year compared with other areas around $200 \mathrm{~mm} /$ year) to tolerate a higher grazing intensity before ecosystem services decreased allows the grassland to provide a greater quantity of provisioning services at the cost of decreased regulating and supporting services. And the grassland restoration needs $7-10$ yeas at least. In the future research, it will be necessary to find ways to identify the key factors that determine these trade-offs so that managers can focus on optimizing those factors. And more field research is encouraged in the future.

\section{References}

Abson D J, Termansen M, 2011. Valuing ecosystem services in terms of ecological risks and returns. Conservation Biology, 25: 250-258.

Bakelaar R G, Odum E P, 1978. Community and population level responses to fertilization in an old-field ecosystem. Ecology, 59: 660-665.

Bao S D, 2000. Soil Chemical Analysis of Agriculture. Beijing: China Agriculture Press. (in Chinese)

Bennett E M, Peterson G D, Gordon L J, 2009. Understanding relationships among multiple ecosystem services. Ecology Letters, 12: 1394-1404.

Brown A J, 1993. A review of soil sampling for chemical analysis. Australian Journal of Experimental Agriculture, 33(8): 983-1006.

Burkhard B, Kroll F, Nedkov S et al., 2012. Mapping ecosystem service supply, demand and budgets. Ecological Indicators, 21: 17-29.

Cheng X L, An S Q, Li G Q et al., 2001. The correlation between the desertification of grassland and the change of vegetation biomass in Erduosi. Scientia Silvae Sinicae, 37(2): 13-20. (in Chinese)

Castro A J, Martin-Lopez B, Lopez E et al., 2015. Do protected areas networks ensure the supply of ecosystem services? Spatial patterns of two nature reserve systems in semi-arid Spain. Applied Geography, 60: 1-9.

Crossman N D, Burkhard B, Nedkov S et al., 2013. A blueprint for mapping and modelling ecosystem services. Ecosystem Services, 4: 4-14.

Dai X G, Xu Y, Jia G et al., 2009. Climate change impact and adaptation in Inner Mongolia. IOP Conference Series: Earth and Environmental Science, 6: 342018.

Daily G, 1997. Nature's Services. Societal Dependence on Natural Ecosystems. Washington D.C: Island Press.

de Groot R S, Wilson M A, Boumans R M J, 2002. A typology for the classification, description and valuation of ecosystem functions, goods and services. Ecological Economics, 41: 393-408.

Deng X Z, Li Z H, Gibson J, 2016. A review on trade-off analysis of ecosystem services for sustainable land-use management. Journal of Geographical Sciences, 26(7): 953-968.

Du B Z, Zhen L, de Groot R et al., 2014. Changing patterns of basic household consumption in the Inner Mongolian grasslands: A case study of policy-oriented adoptive changes in the use of grasslands. The Rangeland Journal, 36(5): 505-517.

Eastwood A, Nijnik M, Brooker R et al., 2013. Nature Conservation and Ecosystem Service Delivery. Peterborough: JNCC Report No. 492.

Eigenbrod F, Armsworth P R, Anderson B J et al., 2010. The impact of proxy-based methods on mapping the distribution of ecosystem services. Journal of Applied Ecology, 47: 377-385.

Evans C R W, Krzic M, Broersma K et al., 2012. Long-term grazing effects on grassland soil properties in southern British Columbia. Canadian Journal of Soil Science, 92(4): 685-693.

Inner Mongolia Statistics Bureau (IMSB), 2013. Rural Statistics Yearbook of Inner Mongolia Autonomous Region in 2010. Hohhot, China: Inner Mongolia Statistics Bureau. (in Chinese)

Inner Mongolia Statistics Yearbook (IMSY), 2015. Beijing: China Statistics Press. (in Chinese).

Ji S J, Geng Y, Li D F et al., 2009. Plant coverage is more important than species richness in enhancing aboveground biomass in a premature grassland, northern China. Agriculture, Ecosystems and Environment, 129: 491-496. 
John R, Chen J Q, Lu N et al., 2008. Predicting plant diversity based on remote sensing products in the semi-arid region of Inner Mongolia. Remote Sensing of Environment, 112(5): 2018-2032.

Kang L, Han X, Zhang Z et al., 2007. Grassland ecosystems in China: Review of current knowledge and research advancement. Philosophical Transactions of the Royal Society of London B: Biological Sciences, 362(1482): 997-1008.

Kareiva P, Tallis H, Ricketts T H et al., 2011. Natural Capital. Theory and Practice of Mapping Ecosystem Services. Oxford: Oxford University Press.

Kumar P, 2010. The Economics of Ecosystems and Biodiversity. London and Washington D.C: Earthscan Publications.

Liu J G, Dietz T, Carpenter S R et al., 2007. Complexity of coupled human and natural systems. Science, 317 : 1513-1516.

MEA (Millennium Ecosystem Assessment), 2003. Ecosystems and Human Well-Being: A Framework for Assessment. Washington D.C: Island Press.

MEA (Millennium Ecosystem Assessment), 2005. Ecosystems and Human Well-being: Synthesis. Washington D.C: Island Press.

Medina-Roldan E, Paz-Ferreiro J, Bardgett R D, 2012. Grazing exclusion affects soil and plant communities, but has no impact on soil carbon storage in an upland grassland. Agriculture, Ecosystems and Environment, 149: $118-123$.

NDRC, 2014. "Opinions on improving the policy of returning grazing to grassland" is the latest guidance to implementing the policy of "returning grazing to grassland", which Joint release by the National Development and Reform Commission, National Ministry of Finance and National Ministry of Agriculture (in Chinese).

Pan Y, Xu Z, Wu J, 2013. Spatial differences of the supply of multiple ecosystem services and the environmental and land use factors affecting them. Ecosystem Services, 5: e4-e10.

Power A G, 2010. Ecosystem services and agriculture: Tradeoffs and synergies. Philosophical Transactions of the Royal Society B: Biological Sciences, 365: 2959-2971.

Prober S M, Thiele K R, Rundel P W et al., 2012. Climate adaptation in intact landscapes: A framework for managing change and resilience applied to the world's largest temperate woodland. Climatic Change, 110: $227-248$.

Raudsepp-Hearne C, Peterson G D, Bennett E M, 2010. Ecosystem service bundles for analyzing tradeoffs in diverse landscapes. Proceedings of the National Academy of Sciences of the United States, 107: 5242-5247.

Rook A J, Dumont B, Isselstein J et al., 2004. Matching type of livestock to desired biodiversity outcomes in pastures: A review. Biological Conservation, 119(2): 137-150.

Shan G L, Xu Z, Ning F, 2008. Influence of exclosure year on community structure and species diversity in a pical steppe. Acta Prataculturae Sinica, 17(6): 1-8. (in Chinese)

Suškevics M, 2012. Legitimacy analysis of multi-level governance of biodiversity: Evidence from 11 case studies across the EU. Environmental Policy and Governance, 22: 217-237.

Swinton S M, Lupi F, Robertson G P et al., 2007. Ecosystem services and agriculture: Cultivating agricultural ecosystems for diverse benefits. Ecological Economics, 64: 245-252.

Tabachnick B G, Fidell L S, 2007. Using Multivariate Statistics. 5th edn. Boston: Allyn and Bacon, Inc.

$\mathrm{Xu}$ Z, Cheng S, Zhen L et al., 2013. Impacts of dung combustion on the carbon cycle of alpine grassland of the north Tibetan Plateau. Environmental Management, 52: 441-449.

Xue Z C, Zhen L, 2018. Impact of rural land transfer on land use functions in western China's Guyuan based on a multi-level stakeholder assessment framework. Sustainability, 10(5): 1376(1-21).

Yan Y, Hu Y, Yue L et al., 2012. Plant diversity change with different land use type and land use intensity: Take Zhengxiangbai Banner as case study. Resources Science, 34(6): 1032-1038. (in Chinese)

Yu F F, Price K P, Ellis J et al., 2003. Response of seasonal vegetation development to climatic variations in eastern central Asia. Remote Sensing of Environment, 87: 42-54.

Zhang Q Y, Wu X H, Zhao D S et al., 2013. Temporal-spatial changes in Inner Mongolian grassland degradation during past three decades. Agricultural Science \& Technology, 14(4): 676-683.

Zhen L, Du B, 2017. Ecological footprint analysis based on changing food consumption in a poorly developed area of China. Sustainability, 9(8): 1323(1-18).

Zhen L, Ochirbat B, Lv Y et al., 2010. Comparing patterns of ecosystem service consumption and perceptions of range management between ethnic herders in Inner Mongolia and Mongolia. Environmental Research Letters, 5: e015001(1-11).

Zhou Z C, Gan Z T, Shangguan Z P et al., 2010. Effects of grazing on soil physical properties and soil erodibility in semiarid grassland of the northern Loess Plateau (China). Catena, 82(2): 87-91. 


\section{Appendix 1 List of potential ecosystem services for assessment based on the results of our literature review}

\begin{tabular}{|c|c|c|c|}
\hline Service/functions & Services & de Groot et al. (2002) & MEA (2005) \\
\hline \multirow{5}{*}{$\begin{array}{l}\text { Production } \\
\text { function/service }\end{array}$} & Food & $\mathrm{X}$ & $\mathrm{X}$ \\
\hline & Raw material & $X$ & \\
\hline & Genetic resources & $\mathrm{X}$ & \\
\hline & Fresh water & & $\mathrm{X}$ \\
\hline & Fuel & & $\mathrm{X}$ \\
\hline \multirow{4}{*}{$\begin{array}{l}\text { Habitat/supporting } \\
\text { service }\end{array}$} & Refugium functions & $\mathrm{X}$ & \\
\hline & Nursery & $\mathrm{X}$ & \\
\hline & Primary production & & $\mathrm{X}$ \\
\hline & Maintenance of genetic diversity & $\mathrm{X}$ & \\
\hline \multirow{10}{*}{$\begin{array}{l}\text { Regulating } \\
\text { function/service }\end{array}$} & Gas regulation & $\mathrm{X}$ & $\mathrm{X}$ \\
\hline & Climate regulation & $\mathrm{X}$ & $\mathrm{X}$ \\
\hline & Pollination & $\mathrm{X}$ & \\
\hline & Water regulation & $\mathrm{X}$ & \\
\hline & Water supply & $\mathrm{X}$ & \\
\hline & Soil retention & $\mathrm{X}$ & \\
\hline & Nutrient regulation & $\mathrm{X}$ & \\
\hline & Disturbance prevention & $\mathrm{X}$ & \\
\hline & Biological control & $\mathrm{X}$ & $\mathrm{X}$ \\
\hline & Water purification & & $\mathrm{X}$ \\
\hline \multirow{5}{*}{$\begin{array}{l}\text { Information/cultural } \\
\text { service }\end{array}$} & Aesthetic information & $\mathrm{X}$ & $\mathrm{X}$ \\
\hline & Recreation & $\mathrm{X}$ & $\mathrm{X}$ \\
\hline & Spiritual and historic information & $\mathrm{X}$ & $\mathrm{X}$ \\
\hline & Cultural and artistic information & $\mathrm{X}$ & \\
\hline & Science and education & $\mathrm{X}$ & $\mathrm{X}$ \\
\hline
\end{tabular}


Appendix 2 Soil properties as a function of study region and land utilization intensity. Abbreviations: AK, available potassium; AN, available nitrogen; AP, available phosphorus; SOM, soil organic matter
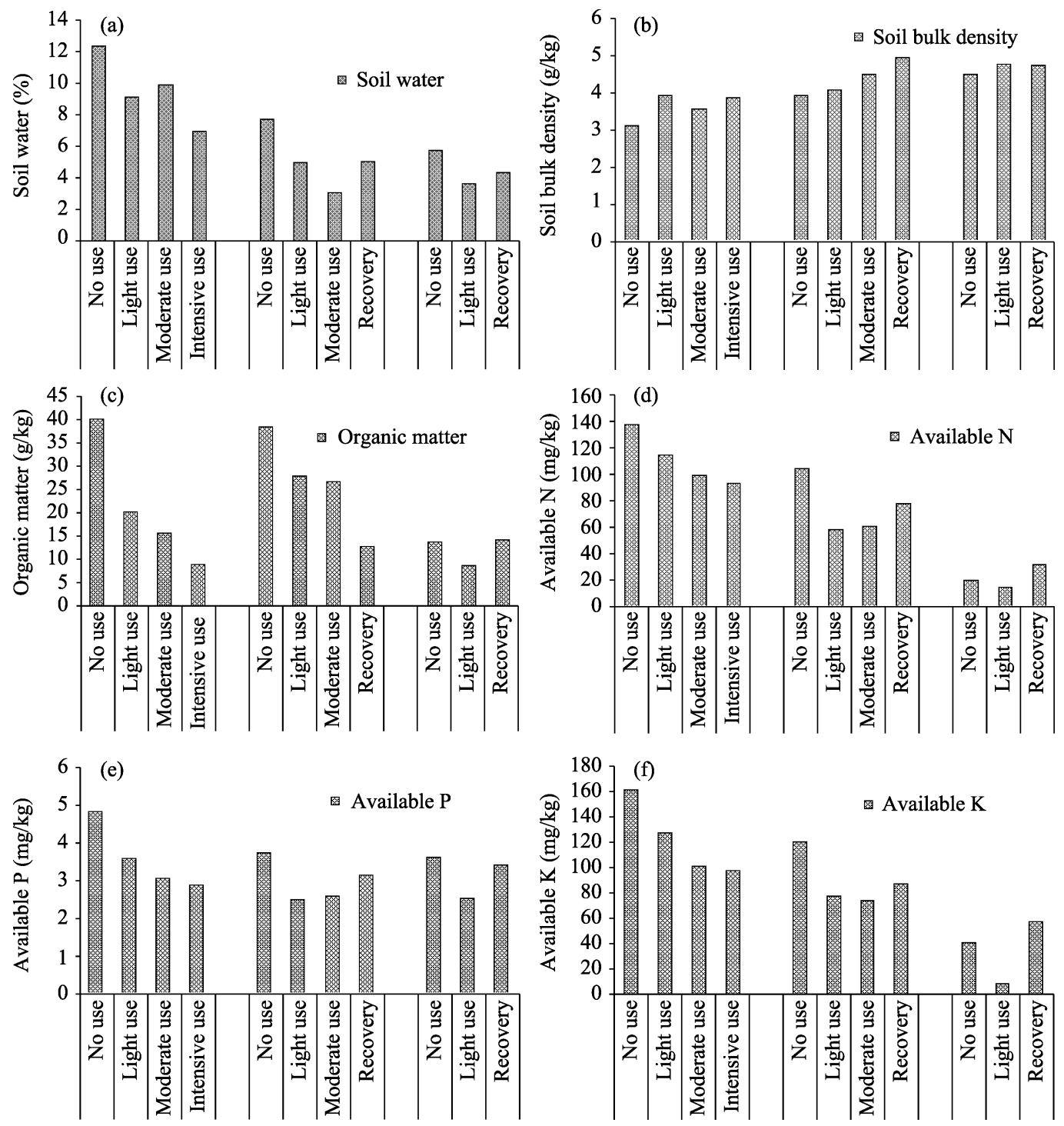
Appendix 3 Vegetation traits as a function of the study region and utilization intensity. (A) Primary production supporting services (AGB, total aboveground biomass). (B) Habitat supporting services (biodiversity)
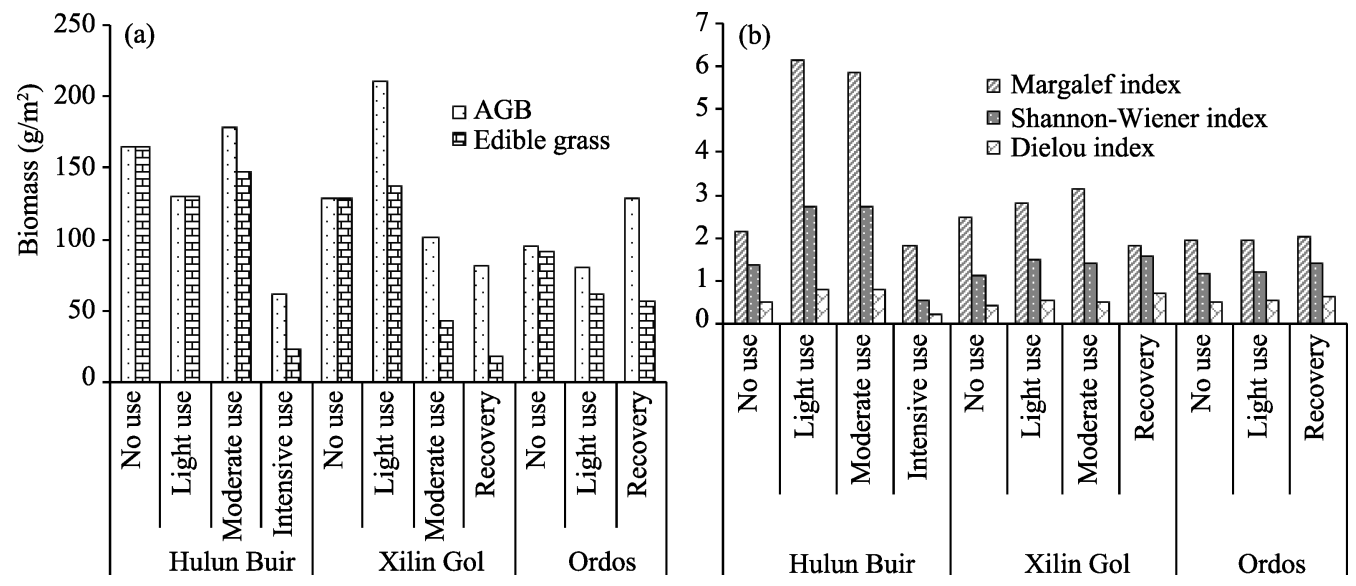